\title{
EFFICACY OF ROLLING BOARD PERTURBATION TRAINING ON BALANCE AMONG HEMIPARETIC STROKE PATIENTS - A COMPARATIVE STUDY
}

Dr. Senthil Kumar*, Dr. Franklin Shaju M.K**, Dr. Vijaya Senthil Kumar*** \& Dr. A. Velmurugan****

${ }^{*}$ Research Scholar, Himalayan University, Itanagar, Arunachal Pradesh, India. **Professor, RVS College of Physiotherapy, Tamil Nadu, India.

***Research Scholar, Himalayan University, Itanagar, Arunachal Pradesh, India. ****Professor, St. John's College of Nursing, Kattappana, Kerala, India. DOI: http://doi.org/10.47211/trr.2020.v06i01.016

\section{ABSTRACT}

Background of the study: Stroke is a major public health problem that ranks in the top four causes of death in most of the countries and is responsible for a large proportion of the burden of neurologic disorders. Patients with stroke have poor balance because they cannot control dynamically the size of the base of support or the location of the line of gravity. Perturbation training undergoes the maximal sway possible without losing his balance.

Objective of the study: The objective of the study is to find the effects of rolling board perturbation training on balance among hemiparetic stroke patients.

Methodology: Thirty clinically diagnosed hemiparetic stroke patients were selected based on the inclusion and exclusion criteria. They were randomly allocated into two groups (Group A and Group B) consists of 15 subjects each. Group A received conventional physiotherapy alone and group B received rolling board perturbation training along with conventional physiotherapy. Intervention lasted for 4 weeks, three days in a week and one hour per day. Balance was measured before and after 4 weeks of intervention by berg balance scale.

Conclusion: Both conventional physiotherapy alone and rolling board perturbation training along with conventional physiotherapy significantly improved balance among hemiparetic stroke patients. When comparing both rolling board perturbation training along with conventional physiotherapy is more effective than conventional physiotherapy alone in improving balance among hemiparetic stroke patients.

Keywords: Hemiparetic stroke, Rolling board perturbation training, Conventional physiotherapy, Balance.

\section{ABOUT AUTHORS:}

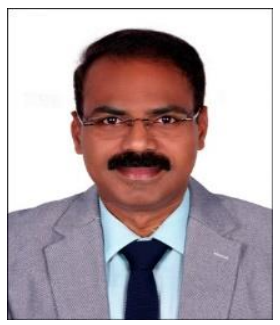

Dr. Senthil Kumar is a former senior lecturer and consultant physiotherapist in the field of physiotherapy since 24 years, having wide knowledge in neuro rehabilitation as a specialty. He is Senior Neuro - Rehab specialist.

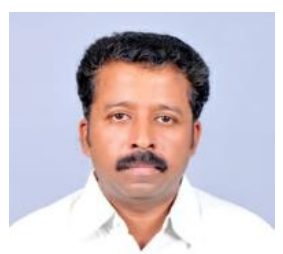

Dr. Franklin is professional Physiotherapist with more than twenty years of experience, deployed in various fields of Physical therapy. He is exposed in research, clinical therapy as well as hands on expertise in classroom grooming as a faculty member. He is the member of Indian Association of Physiotherapists. Currently, he holds the position of Professor, RVS College of Physiotherapy, Coimbatore, Tamil Nadu, India. 


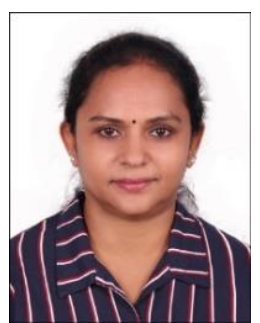

Dr. Vijaya Senthil Kumar is Senior Sports \& Musculoskeletal rehab specialist. She is a former senior lecturer and consultant physiotherapist in the field of physiotherapy since 24 years, having wide knowledge in treating sports and musculoskeletal injuries.

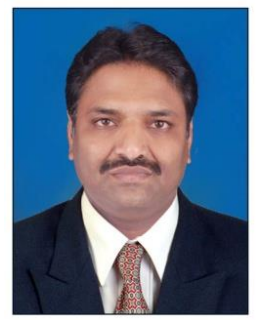

Prof. (Dr.) A. Velmurugan is Ph.D. in Nursing. He began his profession as a clinical instructor, Assistant professor, Associate professor and professor in college of Nursing. He is Head, Department of Medical \& Surgical Nursing, St. John's College of Nursing, Kattappana, Kerala, India.

\section{INTRODUCTION}

Stroke is a major public health problem that ranks in the top four causes of death in most of the countries and is responsible for a large proportion of the burden of neurologic disorders. There are many risk factors for stroke mainly hypertension, diabetes, cardiacdiseases, hypercholesterolemia, cigarette use, and alcohol abuse ${ }^{1}$.

Infarctions of the anterior cerebral artery may present with contra lateral weakness/sensory loss, affecting distal contra lateral leg more than upper extremity².

Stroke is the leading cause of adult disability. Many hemiplegic patients continue with mobility problems due to impaired balance and motor weakness. Re-establishment of balance after a stroke therefore is important. Balance is the ability of the body to remain upright. Patients with stroke have poor balance because they cannot control dynamically the size of the base of support or the location of the line of gravity ${ }^{3}$.

Balance training is very important in stroke rehabilitation protocol. Postural perturbation is a sudden change in conditions that displaces the body posture away from equilibrium. Perturbation training undergoes the maximal sway possible without losing his balance ${ }^{4}$. The purpose of the study is to find the effects of rolling board perturbation training on balance among hemiparetic stroke patients.

\section{METHODOLOGY}

Review Board of Lakshmi Physiotherapy clinic, Coimbatore has approved this two group pre and post-test experimental study and a written consent was obtained from the participants after giving clear instructions regarding the treatment procedure and its implications.

Thirty clinically diagnosed hemiparetic stroke patients age between 50 and 60 were selected consecutively for the study and randomly assigned into anyone of the two experimental groups. Group A fifteen subjects received conventional physiotherapy treatments, it includes active assisted exercises for upper and lower limbs, upper and lower limb activities in sitting and standing, functional Mobility exercises, gait Training and conventional balance exercises. Group B fifteen subjects received rolling board perturbation training along with conventional physiotherapy treatments. The rolling board perturbation training was performed with a standard roller board with $35 \times 38 \mathrm{~cm}$ platform supported by 4 swivel rollers beneath the four corners of the platform. The patients stood on the roller board in affected single limb support while the therapist manually perturbed the roller board randomly in multiple directions, at varying speeds. The displacement of the board during the perturbations varied between approximately 2.5 to $5 \mathrm{~cm}(1-2 \mathrm{in})$. The speed of the perturbations varied from quick displacements to slow, gradual displacements. The activity was initially performed in parallel bars so that the subject would have arm support, if needed. When balance improved, the training was performed outside the parallel bars ${ }^{5}$. Intervention lasted for forty five minutes to one hour per day, three days in a week and the same was continued for 4 weeks. Conventional treatment was given for 45 minutes and rolling board perturbation for 15 minutes in one session. Balance was measured before and after 4 weeks of 
intervention by berg balance scale. All extraneous variables were clearly identified and ruled out from the study.

\section{DATA ANALYSIS AND RESULTS}

The study aims to find the effects of rolling board perturbation training on balance among hemiparetic stroke patients.

Table 1: Mean value, mean difference and paired ' $t$ ' value of balance among group $A$ and $B$ subjects

\begin{tabular}{|l|l|l|l|l|l|}
\hline Balance & $\begin{array}{l}\text { Pre test } \\
\text { Mean }\end{array}$ & $\begin{array}{l}\text { Post test } \\
\text { Mean }\end{array}$ & $\begin{array}{l}\text { Mean } \\
\text { Difference }\end{array}$ & $\begin{array}{l}\text { Standard } \\
\text { Deviation }\end{array}$ & $\begin{array}{l}\text { Paired ' } \\
\text { Value }\end{array}$ \\
\hline Group A & 36.0667 & 44.8000 & 8.7333 & 1.14642 & 18.880 \\
\hline Group B & 35.4000 & 49.4667 & 14.0667 & 1.18723 & 27.016 \\
\hline
\end{tabular}

0.005 level of significance

In group $A$ for balance the calculated paired ' $\mathrm{t}$ ' value is 18.88 and the ' $\mathrm{t}$ ' table value is 2.977 at 0.005 levels. Since the calculated ' $\mathrm{t}$ ' value is more than the ' $\mathrm{t}$ ' table value, there is significant difference between pre and post test scores of balance following conventional physiotherapy alone among hemiparetic stroke patients.

In group B for balance the calculated paired ' $\mathrm{t}$ ' value is 27.016 and the ' $\mathrm{t}$ ' table value is 2.977 at 0.005 level. Since the calculated ' $\mathrm{t}$ ' value is more than the ' $\mathrm{t}$ ' table value, there is significant difference between pre and post test scores of balance following rolling board perturbation training along with conventional physiotherapy among hemiparetic stroke patients.

Table 2: Mean value, mean difference and unpaired ' $t$ ' value of balance among group $A$ and $B$ subjects

\begin{tabular}{|l|l|l|l|l|l|}
\hline \multirow{3}{*}{ Balance } & $\begin{array}{l}\text { Group A } \\
\text { Mean }\end{array}$ & $\begin{array}{l}\text { Group B } \\
\text { Mean }\end{array}$ & $\begin{array}{l}\text { Mean } \\
\text { Difference }\end{array}$ & $\begin{array}{l}\text { Standard } \\
\text { Deviation }\end{array}$ & $\begin{array}{l}\text { Un Paired 't' } \\
\text { Value }\end{array}$ \\
\cline { 2 - 6 } & 8.7333 & 14.0667 & 5.3334 & 1.18723 & 10.951 \\
\hline
\end{tabular}

0.005 level of significance

In between group analysis the calculated unpaired' $\mathrm{t}$ ' values for balance is 10.951 and the ' $\mathrm{t}$ ' table value is 2.763 at 0.005 level. Since the calculated ' $t$ ' value is more than the ' $t$ ' table value there is significant difference between conventional physiotherapy alone and rolling board perturbation training along with conventional physiotherapy in improving balance among hemiparetic stroke patients.

When comparing the mean values of both the groups, group B subjects showed more difference in balance scores than group A subjects.

\section{DISCUSSION}

The results of the present study shows that both conventional physiotherapy alone and rolling board perturbation training along with conventional physiotherapy significantly improved balance among hemiparetic stroke patients. Hemiparetic subjects were involved in the present study as the patients need some amount of balance control to perform rolling board perturbation training. The present study was intended to find whether the rolling board perturbation training cause any significant difference in balance ability among hemiparetic stroke patients.

In the present study balance was improved following both conventional physiotherapy alone and rolling board perturbation training along with conventional physiotherapy. The rolling board perturbation training may provide some protective effect for continued participation in physical activities. Perturbation training techniques may also acquire new motor skills and muscle activity responses will progress from strong cocontraction patterns to more selective muscle activity and movement patterns. During the roller board most subjects appeared to respond with strong co-contractions of lower-extremity muscles during early treatment sessions ${ }^{6}$.

\section{CONCLUSION}

Both conventional physiotherapy alone and rolling board perturbation training along with conventional physiotherapy significantly improved balance among hemiparetic stroke patients. When comparing both perturbations training along with conventional physiotherapy is more effective than conventional physiotherapy alone in improving balance among hemiparetic stroke patients. 


\section{ARTIC LES}

\section{REFERENCES}

1. Amelia K. Boehme, PhD, Charles Esenwa, MD, and Mitchell S. V. Elkind, MD, MS (2018),

2. Stroke Risk Factors, Genetics, and Prevention. NIH Manuscript Submission System, 120(3): 472-495.

3. Robert Teasell MD, Norhayati Hussein MBBS MRehabMed, Ricardo Viana MD, Sarah Donaldson BHSC, Mona Madady MSc (2016), Clinical Consequences of Stroke, Stroke Rehabilitation Clinician Handbook. Page:6.

4. Suruliraj Karthikbabu, Mahabala Chakrapani, Sailakshmi Ganeshan, Kedambadi C Rakshith, Syed Nafeez, and Venkatesan Prem (2013), A review on assessment and treatment of the trunk in stroke a need or luxury, Neural Regeneration Research: 7(25): 1974-1977.

5. Hari Trivedi, Julia A. Leonard, Lena H. Ting, and Paul J. Stapley (2010), Postural responses to unexpected perturbations of balance during reaching. Experimental Brain Research: 202(2): 485-491.

6. G Kelley Fitzgerald, Michael J Axe, Lynn Snyder-Mackler G Kelley Fitzgerald, Michael J Axe, Lynn Snyder-Mackler (2000), The Efficacy of Perturbation Training in Nonoperative Anterior Cruciate Ligament Rehabilitation Programs for Physically Active Individuals. Oxford University press Physical Therapy. Volume 80. Number 2.

7. Vereijkin B, van Emmerik REA, Whiting HTA, Newell KM (1992), Freezing degrees of freedom in skill acquisition, Journal of Motor Behavior: 24:133-142. 